\title{
Personalized medicine and treatment approaches in non-small-cell lung carcinoma
}

This article was published in the following Dove Press journal:

Pharmacogenomics and Personalized Medicine

24 September 2012

Number of times this article has been viewed

\section{Joseph Vadakara \\ Hossein Borghaei}

Fox Chase Cancer Center, Philadelphia, PA, USA
Correspondence: Hossein Borghaei

Fox Chase Cancer Center, 333

Cottman Avenue, Philadelphia,

PA 19।II-2497, USA

$\mathrm{Tel}+\mathrm{I} 2152144297$

$\mathrm{Fax}+\mathrm{I} 2157283639$

Email Hossein.Borghaei@fccc.edu
Abstract: Chemotherapy has been the traditional backbone for the management of metastatic lung cancer. Multiple trials have shown the benefits of treatment with platinum doublets in lung cancer. This "one treatment fits all" approach was further refined by the introduction of targeted agents and discovery of subpopulations of patients who benefited from treatment with these agents. It has also become evident that certain histologic subtypes of non-small-cell lung cancer respond better to one cytotoxic chemotherapy versus others. This has led to the concept of using histology to guide therapy. With the introduction of epidermal growth factor receptor (EGFR) tyrosine kinase inhibitors and the discovery of activating mutations in the EGFR gene, further personalization of treatment for subgroups of patients has become a reality. More recently, the presence of a fusion gene, echinoderm microtubule-associated protein-like 4 anaplastic lymphoma kinase (EML4-ALK), was identified as the driver mutation in yet another subgroup of patients, and subsequent studies have led to approval of crizotinib in this group of patients. In this article, efforts in personalizing delivery of care based on the histological subtypes of lung cancer and the role of K-RAS and EGFR mutations, EML4/ALK translocation, and ERCC1 (excision repair cross-complementing 1) and EGFR expression in choosing appropriate treatments for patients with advanced lung cancer are discussed. This article also reviews the problem of resistance to EGFR tyrosine kinase inhibitors and the ongoing trials that target novel pathways and mechanisms that are implicated in resistance.

Keywords: NSCLC, EGFR, cancer treatment

Lung cancer is affecting an ever increasing number of patients, and is now one of the world's leading causes of cancer-related deaths. There have been many developments in the management of lung cancer, especially in non-small-cell lung cancer (NSCLC). These new treatments take into account the histology and molecular characteristics of the tumor as well as patient characteristics.

The management of NSCLC has historically relied on the use of cytotoxic chemotherapy, and responses have been modest. Advances in our understanding of the tumor biology, along with identification of specific molecular alterations, have allowed a more personalized approach for treatment of some patients with this disease.

In advanced NSCLC, use of platinum doublets has been the accepted standard of care. Studies such as ECOG $1594^{1}$ and SWOG $9509^{2}$ compared several platinum-based doublet regimens and found them to be equally effective, with minor differences in toxicity profile. None of these studies reported a particular advantage in any of the subgroups analyzed. These studies further highlighted the plateau that had been reached in treatment of NSCLC using cytotoxic agents, and indicated a need for change in our 
strategy to address this disease. In this article we review findings that we believe have had the most impact in management of this disease.

\section{Role of histology}

The simplest way of personalizing delivery of care in NSCLC is to use histology. This area had not been fully explored in the past, largely because most of the available agents had equal efficacy in the various histologies. However that changed with the introduction of bevacizumab and pemetrexed.

\section{Bevacizumab}

New blood vessel development is important for tumor growth, and the vascular endothelial growth factor (VEGF) group of proteins is important in the development of new blood vessels. The VEGF family of proteins includes VEGF-A, B, C, D, and E, and placental growth factor 1 and 2. The VEGF proteins, in conjunction with their receptors, act to increase vascular permeability, endothelial cell activation, proliferation, and migration, leading to angiogenesis and subsequent tumor growth and proliferation. ${ }^{3,4}$ Bevacizumab is a humanized mouse monoclonal antibody against VEGF. It binds and inactivates VEGF-A without any effects on the other members of the VEGF family of proteins. ${ }^{5}$ Its clinical efficacy in the treatment of multiple tumor types, including breast, colorectal, renal cell, and glioblastoma, has been established. $^{6-13}$

In an attempt to improve the clinical efficacy of platinum doublets in lung cancer, combination treatments with bevacizumab were explored. In Phase I studies, bevacizumab was shown to be safe in combination with chemotherapy including carboplatin and paclitaxel. ${ }^{14}$ In the pivotal ECOG 4599 trial, the combination of carboplatin/paclitaxel/bevacizumab for up to six cycles, followed by bevacizumab every 3 weeks, until progression, improved the median survival and median progression-free survival (PFS) as compared with carboplatin and paclitaxel alone. Patients with squamous histology were excluded because of the risk of life-threatening bleeding. ${ }^{15}$

\section{Pemetrexed}

Pemetrexed is an antifolate that inhibits the enzyme thymidylate synthase and other folate dependent enzymes. A retrospective analysis of a Phase III trial that compared pemetrexed to docetaxel in patients with recurrent NSCLC indicated superior survival in patients with non-squamous subtypes of NSCLC in the pemetrexed-treated arm. A subsequent Phase III trial in patients with previously untreated advanced NSCLC was then conducted, with a predetermined analysis for histology. ${ }^{16,17}$ This study demonstrated that cisplatin/pemetrexed was non-inferior to the cisplatin/gemcitabine arm in the general patient population, with a median survival of 10.3 months in both arms. However, this predetermined subset analysis based on histology showed that patients with non-squamous histology, adenocarcinoma, large cell carcinoma, and others, tended to have a statistically significant improvement in survival. Survival was reported as 12.6 versus 10.9 months for adenocarcinoma, 10.4 versus 6.7 months for large cell carcinoma, and 11.8 versus 10.4 months for non-squamous overall. An analysis of the squamous subgroup showed that there was a statistically significant detriment to the use of pemetrexed-based regimen, with an overall survival of 9.4 versus 10.8 months favoring the gemcitabine-based regimen.

\section{Nab-paclitaxel}

A recently reported study suggests possible superior response rates in patients with squamous cell histology when treated with nab-paclitaxel. In this Phase III study comparing carboplatin/paclitaxel versus carboplatin/nab-paclitaxel, the combination of nab-paclitaxel/carboplatin had a better response rate in patients with squamous cell carcinoma (41\% versus $24 \%, P<0.001)$ in the nab-paclitaxel arm. ${ }^{18}$ Confirmatory studies are needed with this agent.

\section{Summary}

Use of histology as a means of personalizing chemotherapy in patients with advanced NSCLC is now possible. Although selection of chemotherapy based on histology alone is not the ultimate goal of personalized care, it does avoid unnecessary toxicity in a subset of patients with advanced disease. At this point, the available agents show preferential clinical benefit only in patients with non-squamous histology.

\section{Molecular targets in lung cancer, suppressing the identifiable oncogenic drivers}

Identification of several driver mutations and a translocation in NSCLC tumors has led to development of two drugs that have had a major impact on the treatment of patients with such tumors. The main driver mutations in lung cancer are seen in several genes including epidermal growth factor receptor (EGFR), K-RAS, and MEK. The echinoderm microtubule-associated protein-like 4 - anaplastic lymphoma kinase (EML4-ALK) translocation, EGFR expression determined by immunohistochemistry (IHC), and excision repair 
cross-complementing (ERCC) expression are additional determinants of response to various agents.

\section{K-RAS mutation}

The K-RAS mutation was first described in human lung cancers in the 1980s, where it was found in tumor tissue but not in normal host tissues. ${ }^{19}$ The Ras family belongs to the super-family of guanosine triphosphatases (GTPases) and is composed of several members. Different stimuli from cell surface, through activation of various proteins, can activate members of this family. Once activated, Ras protein stimulates the initiation of several signaling cascades. In the case of K-RAS, these include: Raf/MEK/ERK (promoting proliferation) and PI3K/Akt (inhibiting apoptosis). Stimulation of EGFR also activates K-RAS.

K-RAS mutations have been found in approximately $17 \%$ of all NSCLC, and are seen in $27 \%-34 \%$ of adenocarcinomas and non-squamous tumors, but are rarely seen in squamous cell carcinomas..$^{20,21}$ As a predictor of prognosis, data from several clinical trials indicate that having a K-RAS mutation may be associated with a poorer overall prognosis. A meta-analysis of studies looking into survival of patients with lung cancer and K-RAS mutations showed decreased overall survival for patients with this mutation, with a hazard ratio (HR) of 1.35 (95\% confidence interval [CI] 1.16-1.56). In adenocarcinomas, the HR was 1.59 (95\% CI 1.26-2.02). ${ }^{22}$ A retrospective study based on tumor samples from the ECOG 3590 study, in which patients were randomized to either postoperative radiotherapy or chemoradiotherapy, showed no statistically significant difference in survival in wild-type versus mutant K-RAS tumors. However, a multivariate analysis looking at prognostic factors found that K-RAS mutational status was a weak prognostic factor (relative risk $0.641, P=0.066){ }^{21}$

In the JBR.10 study, where the use of adjuvant chemotherapy with cisplatin/vinorelbine versus observation in patients with resected lung cancer was examined, survival of patients with tumors that expressed wild-type K-RAS was prolonged by adjuvant chemotherapy compared with observation $(\mathrm{HR}=0.69 ; 95 \%$ CI $0.49-0.97 ; P=0.03)$. However, there was no apparent benefit from chemotherapy in patients with tumors that expressed K-RAS mutations $(\mathrm{HR}=0.95$; $95 \%$ CI $0.53-1.71 ; P=0.87) .{ }^{23}$ In the SATURN trial, which investigated the use of erlotinib as maintenance in patients who had stable or nonprogressive disease after treatment with four cycles of a platinum doublet, presence of K-RAS mutation was associated with a poorer PFS. ${ }^{24}$ Multiple other studies have also indicated that patients treated with
EGFR inhibitors such as erlotinib and gefitinib in the presence of K-RAS mutations have poorer response rates and survival. ${ }^{25-28}$

Targeting of K-RAS as a therapeutic target has been difficult. Several strategies have been employed. One approach with early promise relied on the use of drugs that belonged to the class of farnesyl transferase inhibitors, which prevent post-translational modification and farnesylation of a wide variety of proteins, including RAS. However, clinical trials of many of these compounds have failed to show significant benefits. ${ }^{29,30}$ Another compound with early promise was farnesylthiosalicylic acid, or salirasib, which decreases the activity of activated RAS by competitively inhibiting the attachment of GTP-bound RAS to the plasma membrane. This compound has failed to show any benefit in Phase II trials. ${ }^{31}$ Perhaps a more practical strategy is targeting pathways that are downstream or parallel to K-RAS, which may be easier to target. These include RAF, MEK, and PI3K/Akt, mTor, or c-MET.

Table 1 gives a listing of current clinic trials with different molecularly targeted agents aimed at K-RAS mutated tumors. Figure 1 shows a simplified schema for pathways that are important in lung cancer.

\section{EGFR mutations}

The EGFR is a transmembrane receptor that belongs to the HER/erb family of receptor tyrosine kinases, which includes HER1, HER2, HER3, and HER4. When activated by its ligand, it undergoes homo- or heterodimerization with other family members, resulting in phosphorylation of the cytoplasmic domain and downstream signaling through multiple pathways, activating gene transcription, cell growth, and proliferation. ${ }^{32}$ EGFR tyrosine kinase inhibitors (EGFR TKI), erlotinib and gefitinib, are well tolerated oral agents that have been tested in multiple trials. ${ }^{33-42}$

The most significant advancement in this area has been the discovery of activating mutations in the EGFR gene. This finding, confirmed independently by two groups, has had a significant impact in personalizing treatment of advanced NSCLC. These groups showed that the response to TKI therapy correlated with the presence of activating mutations present in the tyrosine kinase domain of the EGFR receptor. Exons 18 to 21 of the EGFR gene codes for the tyrosine kinase portion of the EGFR receptor, and mutations in any of these regions may confer either sensitivity or resistance to EGFR TKI directed therapy. The most common mutation is a deletion in exon 19. The second most common type of mutation is point mutations in exon 21 , the most common 
Table I Proposed mechanisms of action of drugs in clinical trials addressing K-RAS mutated tumors

\begin{tabular}{|c|c|c|c|}
\hline Mechanism of action & Drug name & Clinical trial & Tumor characteristics \\
\hline \multirow[t]{3}{*}{ MEK inhibitor } & Selumetinib/AZD6244 & $\begin{array}{l}\text { NCTOI229I50, NCT00890825, } \\
\text { NCT0I } 239290\end{array}$ & k-RAS mutated NSCLC \\
\hline & GSKII 20212 & NCT0I362296, NCT00687622 & k-RAS mutated NSCLC \\
\hline & MEKI62 & $\begin{array}{l}\text { NCTOI337765, NCTOI449058, } \\
\text { NCT0I363232, NCT00959I } 27\end{array}$ & $\begin{array}{l}\text { Tumors with k-RAS, } \\
\text { NRAS, and/or BRAF } \\
\text { mutations }\end{array}$ \\
\hline c-MET inhibitor & ARQ 197 & NCT0I395758 & k-RAS mutated NSCLC \\
\hline \multirow[t]{2}{*}{ mTOR inhibitor } & Retaspimycin $\mathrm{HCl}(\mathrm{IPI}-504)$ +everolimus & NCT0I427946 & k-RAS mutated NSCLC \\
\hline & Ridaforolimus & NCT008I8675 & k-RAS mutated NSCLC \\
\hline mTor+ PI3K inhibitors & BEZ235 & NCT0I 337765 & $\begin{array}{l}\text { Tumors with k-RAS, } \\
\text { NRAS, and/or BRAF } \\
\text { mutations }\end{array}$ \\
\hline \multirow[t]{2}{*}{ PI3K inhibitor } & BYL7I9 & NCT0I449058 & $\begin{array}{l}\text { Tumors with k-RAS, } \\
\text { NRAS, and/or BRAF } \\
\text { mutations }\end{array}$ \\
\hline & BKMI20 & NCT0I 363232 & $\begin{array}{l}\text { Tumors with k-RAS, } \\
\text { NRAS, and/or BRAF } \\
\text { mutations }\end{array}$ \\
\hline HSP90 inhibitor & Retaspimycin $\mathrm{HCl}(\mathrm{IPI}-504)+$ everolimus & NCT0I427946 & k-RAS mutated NSCLC \\
\hline $\begin{array}{l}\text { Virus killing Ras } \\
\text { activated cells }\end{array}$ & $\begin{array}{l}\text { Reovirus serotype 3-Dearing strain } \\
\text { (REOLYSIN) }\end{array}$ & NCT0086I627 & k-RAS mutated NSCLC \\
\hline $\begin{array}{l}\text { Recombinant mutant } \\
\text { Ras protein }\end{array}$ & GI-4000 & NCT00655I6I & k-RAS mutated NSCLC \\
\hline
\end{tabular}

of these being L858R. Besides mutations in these exons, there can be activating mutations in exon 18 and exon 20 , but these are much less common. Most mutations in exon 20 are associated with a resistance to TKI. ${ }^{43-45}$

Initial studies with EGFR TKIs enrolled all-comers without any knowledge of the mutational status of patients. BR.21 was a large, randomized, placebo-controlled, doubleblind Phase III trial that evaluated the efficacy of erlotinib versus placebo in patients with previously treated NSCLC. A reported median PFS of 2.2 months in the erlotinib group versus 1.8 months in the placebo arm led to the approval of this agent. The median overall survival was 6.7 and 4.7 months in the erlotinib and placebo arms, respectively. A subsequent subgroup analysis showed that the maximum benefit was seen in women $(P=0.006)$, nonsmokers $(P<0.001)$, Asians $(P=0.02)$, and adenocarcinoma histology $(P<0.001))^{33}$

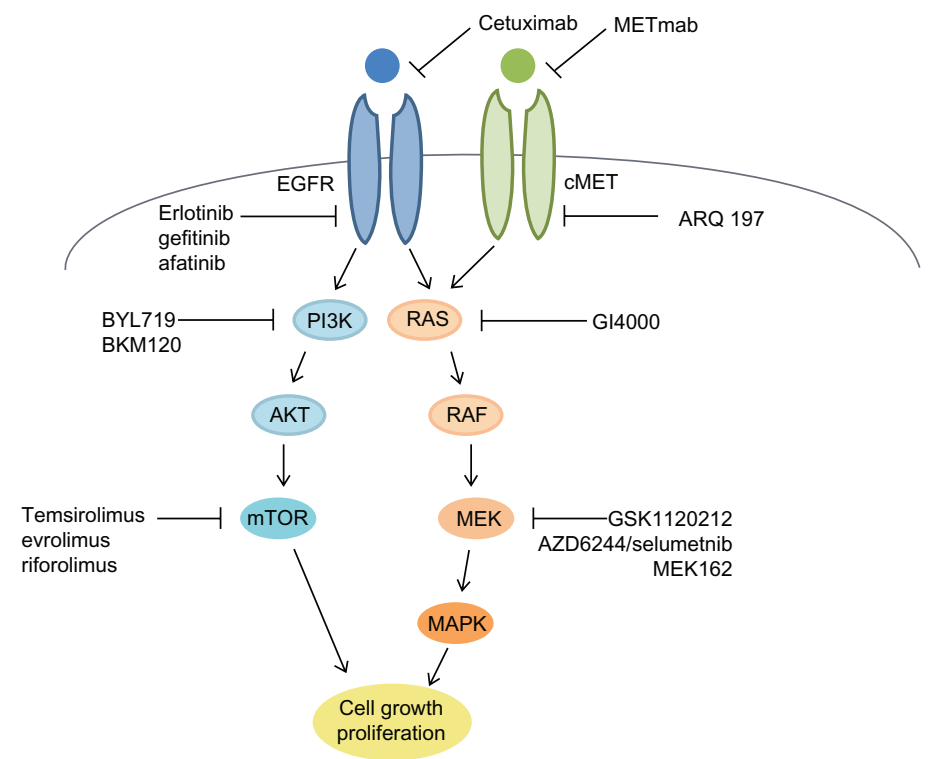

Figure I Simplified schema of molecular pathways involved in lung cancer with proposed mechanisms of action of established and newer agents. 
We now know that these groups have a higher likelihood of harboring EGFR-activating mutations, and are therefore more likely to respond to TKI therapy.

Attempts at combining either erlotinib or gefitinib with chemotherapy have not been successful. These studies for the most part have enrolled patients without prior knowledge of their mutational status. ${ }^{46-49}$

The IPASS trial (Iressa Pan-Asia Study) was an openlabel Phase III study that compared gefitinib $250 \mathrm{mg}$ daily with carboplatin/paclitaxel every 3 weeks for up to six cycles, in previously untreated patients with NSCLC. The mutational status of the patients was not known at study entry but was determined if adequate tissue was available during the study. In the subgroup of patients with activating EGFR mutations, gefitinib had a superior PFS (HR for progression $=0.48 ; 95 \%$ CI $0.36-0.64 ; P<0.001)$. The objective response rate was $71.2 \%$ with gefitinib, versus $47.3 \%$ with carboplatin-paclitaxel, in the mutation-positive subgroup $(P<0.001) .{ }^{50}$ Maemondo et al conducted a Phase III trial that also compared gefitinib $250 \mathrm{mg}$ to carboplatin/paclitaxel in patients with sensitive EGFR mutations. This study also demonstrated a significantly increased median PFS, 10.8 versus 5.4 months in the gefitinib and chemotherapy arms respectively (HR $0.30 ; 95 \%$ CI $0.22-0.41 ; P<0.001$ ). The response rate, similar to the IPASS study, was also significantly higher (73.7\% versus $30.7 \%)$ in the gefitinib arm $(P<0.001) .{ }^{51}$ Most of these studies were conducted in Asia and used gefitinib as the study agent. The OPTIMAL study, a Phase III study that compared erlotinib to carboplatin/ gemcitabine, in patients with advanced NSCLC harboring activating EGFR mutations, also yielded a median PFS that was significantly superior in the erlotinib arm compared with the chemotherapy arm (13.1 versus 4.6 months; HR 0.16 , 95\% CI $0.10-0.26 ; P<0.0001) .{ }^{52}$ Similar results were seen in the EURTAC trial, another Phase III study that compared erlotinib and platinum-based chemotherapy in patients with activating EGFR mutations. ${ }^{53} \mathrm{In}$ all of these studies, use of an EGFR TKI in the front-line setting showed a good response rate, in excess of 50\%, and a statistically significant improvement in PFS. Table 2 summarizes Phase III data looking at the use of EGFR TKIs in the first-line setting in advanced NSCLC.

Together, these studies establish the role of EGFR TKIs in treatment of patients with EGFR-activating mutations at the time of diagnosis. It is imperative to obtain molecular markers on all patients with adenocarcinomas in an attempt to tailor treatment based on their tumor characteristics beyond histology.

\section{Detection methods}

There are multiple methods that help identify various mutations in the EGFR gene. Once the tissue is deemed adequate, DNA is extracted for analysis; this step is crucial, as an unreliable process can lead to inaccurate results. Purified DNA is then amplified using different techniques before it is tested for mutations. Testing for mutations is accomplished using two basic methodologies. One approach is to screen the EGFR gene for all mutations both known and unknown;

Table 2 Phase III studies with EGFR TKIs in the first-line setting in advanced NSCLC

\begin{tabular}{|c|c|c|c|}
\hline Study & Population studied & Treatment arms & Results \\
\hline IPASS $^{50}$ & Adenocarcinoma & $\begin{array}{l}\text { Carboplatin/paclitaxel vs } \\
\text { Gefitinib }\end{array}$ & $\begin{array}{l}\text { Intention to treat group had a } \mathrm{HR}=0.74 ; 95 \% \mathrm{CI}, 0.65-0.85 ; \\
P<0.00 \mathrm{I} \text {. } \\
\text { EGFR mutated group had a } \mathrm{HR}=0.48 ; 95 \% \mathrm{CI}, 0.36-0.64 ; \\
P<0.00 \mathrm{I} \text {. } \\
\text { Response Rate was } 7 \mathrm{I} .2 \% \text { vs } 47.3 \%,(P<0.00 \mathrm{I}) \text { in the Gefitinib } \\
\text { and chemotherapy groups respectively, within the EGFR } \\
\text { mutated subgroup. }\end{array}$ \\
\hline NEJSG $002^{51}$ & $\begin{array}{l}\text { EGFR activating } \\
\text { mutation positive }\end{array}$ & $\begin{array}{l}\text { Carboplatin/paclitaxel vs } \\
\text { gefitinib }\end{array}$ & $\begin{array}{l}\text { Gefitinib group had a } \mathrm{HR}=0.30 ; 95 \% \mathrm{Cl}, 0.22-0.4 \mathrm{I} ; P<0.00 \mathrm{I} \text {. } \\
\text { Response rate was } 73.7 \% \text { vs } 30.7 \%,(P<0.00 \mathrm{I}) \text { in the Gefitinib } \\
\text { and chemotherapy arms respectively. }\end{array}$ \\
\hline WJTOG3405 54 & $\begin{array}{l}\text { EGFR activating } \\
\text { mutation positive }\end{array}$ & $\begin{array}{l}\text { Cisplatin/docetaxel vs } \\
\text { gefitinib }\end{array}$ & $\begin{array}{l}\text { Gefitinib group had a } \mathrm{HR}=0.489 ; 95 \% \mathrm{Cl}, 0.336-0.710 ; P<0.000 \mathrm{I} \text {. } \\
\text { Response rate was } 62.1 \% \text { vs } 32.2 \%(P<0.000 \mathrm{I}) \text { in the Gefitinib } \\
\text { and chemotherapy arms respectively. }\end{array}$ \\
\hline $\begin{array}{l}\text { OPTIMAL } \\
(\text { CTONG-0802) }\end{array}$ & $\begin{array}{l}\text { EGFR activating } \\
\text { mutation positive }\end{array}$ & $\begin{array}{l}\text { Gemcitabine/carboplatin vs } \\
\text { erlotinib }\end{array}$ & $\begin{array}{l}\text { Erlotinib group had a } \mathrm{HR}=0.16 ; 95 \% \mathrm{Cl}, 0.10-0.26 ; P<0.000 \mathrm{I} \text {. } \\
\text { Response rate was } 83 \% \text { vs } 36 \%(P<0.000 \mathrm{I}) \text { in the Erlotinib } \\
\text { and chemotherapy arms respectively. }\end{array}$ \\
\hline EURTAC 53 & $\begin{array}{l}\text { EGFR activating } \\
\text { mutation positive }\end{array}$ & Platinum doublet vs erlotinib & $\begin{array}{l}\text { Erlotinib group had a } \mathrm{HR}, 0.80 ; P=0.42 \text {. } \\
\text { Response rate was } 54.5 \% \text { vs } 10.5 \%(P<0.0001) \text { in the Erlotinib } \\
\text { and chemotherapy arms respectively. }\end{array}$ \\
\hline
\end{tabular}


this method usually needs a greater proportion of tumor cells in the sample. Examples of this approach are polymerase chain reaction (PCR) and direct sequencing, melting analysis, and pyrosequencing. ${ }^{55,56}$ In general, these methods take additional time and need a greater percentage of tumor cells in the sample, and therefore would require a larger pathological specimen; however, novel mutations can be detected using this method. The second approach is to look for specific known mutations. This approach tends to be more sensitive and requires less tissue; however, the disadvantage of this method is that it can detect only known mutations. Examples of this approach are ARMS (amplification refractory mutation system), PNA clamp (peptide nucleic acid clamp), SNaPshot (a multiplexed PCR-based assay), ME PCR (mutation-enriched PCR), and PCR invader. ${ }^{57-60}$ The choice of testing method may be controlled by institutional preferences; however, this should take into account the size and quality of the tumor sample and the likelihood of false negatives and false positives. ${ }^{61}$

\section{Resistance to EGFR TKIs}

Inherent or primary resistance to EGFR TKIs can occur as a result of a mutation in the EGFR TK domain. The most common mutation is an insertion in exon 20, and rarely a mutation in exon $19 .{ }^{62}$ All of these mutations are rare, and it is much more likely that there are additional mutations in downstream pathways such as K-RAS, or amplification in parallel pathways.

Secondary or acquired resistance occurs after a period of response to EGFR-targeted therapy. The most common mutation is the T790M mutation, a point mutation in exon 20 resulting in substitution of a threonine residue with methionine, seen in about $50 \%$ of tumors that relapse after exposure to EGFR TKIs. Some studies have suggested that this mutation is already present in some tumor cells even before exposure to the drug, and that treatment leads to selection of the mutated clone. ${ }^{62,63}$ Another acquired mutation has recently been reported in exon 21 . This change leads to substitution of alanine for threonine at position 854 (T854A) and interferes with the inhibition of tyrosine phosphorylation by erlotinib. ${ }^{64}$

To address the issue of resistance, second generation EGFR TKIs have been developed. These agents are irreversible inhibitors and covalently bind to Cys-797 of the EGFR ATP binding domain, and they seem to overcome resistance introduced by the $T 790 \mathrm{M}$ mutation that is seen with gefitinib and erlotinib. The frontrunners in the development of second generation irreversible TKIs are BIBW 2992 (afatinib) and PF00299804.
Afatinib inhibits both EGFR and HER2 and has been found to be very active in NSCLC with EGFR mutations. ${ }^{65}$ Interestingly, it has also been found to be effective in treating patients with de novo T790M mutations. ${ }^{66}$ In a Phase IIb/III double-blind placebo-controlled trial of afatinib in patients who had failed 1-2 lines of chemotherapy and either erlotinib or gefitinib plus best supportive care compared with placebo with best supportive care, afatinib showed a statistically significant PFS and response rates compared with placebo. ${ }^{67}$ In a single-arm Phase II study in patients who progressed after erlotinib or gefitinib, afatinib showed significant benefits in terms of disease control rate and a median PFS of 4.4 months. This study was conducted in a highly enriched population of patients with previously known EGFR mutations. ${ }^{68}$ More recently, a combination of afatinib and cetuximab, allowing for a complete EGFR blockade, has shown clinical benefit with a $36 \%$ partial response (PR) rate overall and a $29 \%$ PR rate in confirmed T790M mutations. ${ }^{69}$

PF00299804 is a pan HER inhibitor, targeting EGFR, HER2, and HER4. In preliminary studies, it has been shown to be effective in patients with EGFR mutations in the firstline setting. ${ }^{70}$ In a randomized Phase II study comparing it with erlotinib in patients with NSCLC following progression on chemotherapy, an overall PFS advantage was achieved..$^{71,72}$ A phase I/II study of this agent in Asian patients who were refractory to chemotherapy and erlotinib or gefitinib, showed antitumor activity without significant toxicity. ${ }^{73}$ Further studies with this agent are pending.

Another important determinant of resistance to EGFR therapy is c-MET expression. MET amplification can lead to secondary or primary resistance in patients with EGFR TKI sensitive mutations. MET amplification has been seen in approximately $20 \%-22 \%$ of lung cancer tissue samples that had become resistant to erlotinib or gefitinib, compared with only about $3 \%$ of untreated patients. This resistance is thought to be secondary to HER3-mediated activation of the PI3K-AKT pathway. ${ }^{74,75}$

MetMAb (Genentech, Inc, South San Francisco, CA) is a monovalent antibody that targets c-MET and prevents its activation by hepatocyte growth factor. Patients with recurrent advanced NSCLC were randomly assigned to treatment with erlotinib versus erlotinib and MetMAb in a randomized Phase II trial. High expression of c-MET (defined as a majority of tumor cells with $\geq 50 \%$ MET expression by IHC) was associated with statistically superior PFS (1.5 versus 3.0 months, $P=0.01$ ), and overall survival (4.6 months versus 12.6 months, $P=0.002$ ) in favor of the MetMAb arm. 
However, in c-MET low expressing patients, PFS was better in the erlotinib treatment arm (9.2 months versus 5.5 months, $P=0.021){ }^{76}$

Other MET inhibitors have also been tested in NSCLC. A recent Phase II trial looked at combining erlotinib with tivantinib (ARQ197) in patients who have received at least one line of therapy that did not include a TKI. The study did not meet its primary endpoint of superior PFS, but subset analysis showed that it had benefit in K-RAS mutated patients. A Phase III trial, MARQUEE (Met inhibitor ARQ 197 plus erlotinib versus erlotinib plus placebo in NSCLC) is underway to further clarify the role of ARQ 197 in this population. ${ }^{77}$

\section{Resistance to chemotherapy}

Chemotherapeutic agents were designed with the rationale that rapidly dividing cells are more sensitive to DNA damage. A number of DNA repair genes have been studied and are under investigation as potential targets to improve the therapeutic index of existing cytotoxic agents. Aberrant activation of DNA repair in response to chemotherapy-induced DNA damage is a major mechanism of drug resistance. As an example, the ATM (ataxia telangiectasia mutated) and ATR (ataxia telangiectasia Rad3-related) kinases have been identified as important triggers of chemotherapy resistance. These proteins are required for DNA repair in response to DNA damage and are required for cell cycle arrest. ATM and ATR regulate a series of proteins that prevent initiation of DNA replication. ${ }^{78}$ Therefore, targeting specific signaling component of the DNA damage response can increase efficacy of chemotherapy. This approach is being actively tested using several agents. ${ }^{79}$

In lung cancer, one of the best studied pathways is the excision repair cross-complementation group 1 (ERCC-1). ERCC-1 is needed for DNA damage repair following exposure to platinum compounds like cisplatin and carboplatin. A low level of expression of ERCC-1 suggests that tumors may not be able to repair platinum-induced damage. A retrospective analysis of ERCC-1 expression in resected specimens of patients enrolled in the International Adjuvant Lung Cancer Trial (IALT ) study showed that ERCC-1 negative patients had a better overall survival in the chemotherapy arm, with a median overall survival of 56 months compared with 42 months in the control arm. In ERCC- 1 positive patients there was no apparent benefit to adjuvant chemotherapy. ${ }^{80}$ Randomized studies in which patients are assigned to various treatments based on the level of ERCC-1 expression are ongoing.

\section{EML4-ALK translocation}

The EML4-ALK gene rearrangement is a relatively new finding in lung cancer and was first reported in 2007. In this translocation, a deletion and translocation in chromosome $2 p$ brings the EML4 gene in conjunction with ALK receptor tyrosine kinase, making a fusion protein in which the tyrosine kinase activity is permanently turned on. ${ }^{81}$ EML4-ALK rearrangement is detected in approximately $5 \%$ of patients with adenocarcinomas. Like EGFR mutations, EML4-ALK positive tumors are usually seen in nonsmokers or very light smokers, and tend to be adenocarcinomas. Crizotinib, a C-MET inhibitor, was found to have significant activity in patients with tumors that expressed EML4/ALK rearrangement in a Phase I trial. ${ }^{82}$ Based on the results of this Phase I study, an enriched population of ALK-positive patients were added to the study. The overall response rate was $57 \%$, with $27 \%$ of the patients having stable disease. The disease control rate over a period of 8 weeks was $87 \% .{ }^{83}$ PFS in 119 patients in this Phase I study was 10 months (95\% CI 8-15 months), and the median overall survival had not been reached. ${ }^{84}$ Two subsequent Phase II studies looked at the use of crizotinib in ALK + NSCLC. The first Phase II study involved 117 patients with ALK + advanced NSCLC. Two complete responses (CRs) and 69 PRs for a response rate of $61 \%(95 \%$ CI $52 \%-70 \%)$, with the median response duration of 48.1 weeks, have been reported. In the second Phase II single-arm study of 136 ALK-positive patients, there was $1 \mathrm{CR}$ and $67 \mathrm{PRs}$ with a response rate of $50 \%$ (95\% CI 42\%-59\%), and a median response duration of 41.9 weeks. Based on these two studies, the Food and Drug Administration granted approval for the use of crizotinib in ALK + NSCLC. ${ }^{85}$ Clinical trials with other ALK inhibitors are now ongoing and are summarized in Table 3.

\section{Detection methods}

Different methods have been used to test for EML4-ALK rearrangements. These include fluorescent in situ hybridization (FISH) probes, IHC for ALK expression and reverse transcriptase (RT)-PCR. The current gold standard for EML4ALK testing is FISH. IHC was found to be concordant with FISH in the highly positive patients, but the concordance was not high in samples that stained weakly or moderately. ${ }^{86,87}$ RT-PCR can help determine the partner gene and potential variants depending on the breakpoints; however, it will only detect specific breakpoints and may miss those that are not being looked for. Currently, the approved test in the United States is the FISH-based test. ${ }^{88}$ 
Table 3 Current ALK inhibitors in clinical trials in various tumor types

\begin{tabular}{llll}
\hline LDK378 & NCT0I2835I6 & Phase I & Tumors with ALK \\
IPI-504 HSP 90 inhibitor & NCT0I228435 & Phase II & ALK + lung cancer \\
AP26II3 (ALK/EGFR inhibitor) & NCT0I44946I & Phase I/II & ALK + or EGFR + lung Ca \\
PF-0234I066 (c-Met Alk inhibitor) & NCT00585I95 & Phase I & ALK + lymphoma \\
PF-0234I 1066 (c-Met Alk inhibitor) & NCT00932893 & Phase III & ALK + lung cancer second line \\
\hline
\end{tabular}

\section{Role of EGFR expression}

EGFR expression, unlike EGFR activating mutations, is seen in about $62 \%$ of NSCLC patients, with maximum expression seen in squamous cell carcinoma ( $82 \%)$ and bronchoalveolar carcinomas (80\%). In a univariate analysis, the presence of EGFR overexpression or increased copy number did not affect patients' prognosis, but there was a trend towards a less favorable prognosis. ${ }^{89}$

In the Phase III FLEX trial, patients with EGFRexpressing tumors were randomly assigned to receive cisplatin/vinorelbine or cisplatin/vinorelbine plus cetuximab. The median PFS was 11.3 versus 10.1 months in the chemotherapy plus cetuximab arm and chemotherapy alone arm respectively $(\mathrm{HR}=0.871,95 \% \mathrm{CI} 0.762-0.996, P=0.044) .{ }^{90}$ EGFR expression was defined as having any expression by IHC. The BMS 099 trial investigated the use of a carboplatin/paclitaxel combination with or without cetuximab in patients who were not selected for EGFR expression. This study failed to show any improvement in PFS or overall survival. ${ }^{91}$ A retrospective analysis of the FLEX data, based on the level of EGFR expression in tumors as defined by the $\mathrm{H}$ score method, was recently published. In this analysis an $\mathrm{H}$ score $\geq 200$ defined a high expressing tumor. Based on this definition, overall survival was better in the chemotherapy plus cetuximab arm in high versus low expressing tumors, with a median overall survival of 12.0 months compared with 9.6 months in the chemotherapy alone group..$^{92}$ This analysis suggests that better patient selection based on the level of EGFR expression, as defined by $\mathrm{H}$ score, might select a patient population that would benefit from Cetuximab treatment. This observation needs to be confirmed in a randomized prospective trial.

\section{Discussion}

There has been a great deal of progress in the management of NSCLC, from selection of initial chemotherapy in the adjuvant setting based on histology and molecular characteristics to multi-targeted agents in the refractory, relapsed, and metastatic settings. Molecular features of the tumor are now guiding therapy, and there has been an explosion of targeted therapies based on a better understanding of driver mutations and pathways of resistance. The coming years will see the use of next-generation TKIs like afatinib in addition to erlotinib, gefitinib, and crizotinib. Studies like the International Tailored Chemotherapy Adjuvant (ITACA) and Tailored Post-Surgical Therapy in Early Stage NSCLC (TASTE) trials will also help to further refine adjuvant chemotherapy based on predicted tumor response to chemotherapy, making it more personalized and individualized.

It is important to emphasis several points in this setting. The clinically useful drivers of personalized medicine in this disease that are validated either by larger Phase III trials or have regulatory approval fall into two categories; those driven by histology (bevacizumab and pemetrexed) and those driven by molecular markers (erlotinib and crizotinib). In the case of bevacizumab, the personalization of delivery of care is due to a toxicity factor in one histology, and in the case of pemetrexed, it is by preferential activity in nonsquamous histologies. Although there is much interest in and there is availability of testing for markers such as ERCC-1, there are no prospective Phase III trials or regulatory approval for the use of this test in the clinical decision-making process. Given the enormous interest in and availability of molecular testing, much of which is for markers that are not validated, caution should be used in interpreting the results and basing clinical decision making on untested markers.

We have a much better understanding of some of the driver mutations that impact patient outcome in lung cancer. In the coming years our ability to target pathways of interest as opposed to individual genes will open new possibilities for treatment. Use of system biology and studies using synthetic lethal interactions continue to identify close associations between genes that operate in related or redundant pathways. These investigations could ultimately lead to rationally designed clinical trials with combination therapies with multiple targeted agents. Management of toxicities and cost will then be challenges that need to be addressed. The future, however, is promising.

\section{Disclosure}

Houssein Borghaei is a speaker at Genentech, Speaker Bureau. Joseph Vadakara has no conflicts of interest in this work. 


\section{References}

1. Schiller JH, Harrington D, Belani CP, et al. Comparison of four chemotherapy regimens for advanced non-small-cell lung cancer. N Engl J Med. 2002;346(2):92-98.

2. Kelly K, Crowley J, Bunn PA, et al. Randomized Phase III trial of paclitaxel plus carboplatin versus vinorelbine plus cisplatin in the treatment of patients with advanced non-small-cell lung cancer: a Southwest Oncology Group trial. J Clin Oncol. 2001;19(13):3210-3218.

3. Hicklin DJ, Ellis LM. Role of the vascular endothelial growth factor pathway in tumor growth and angiogenesis. J Clin Oncol. 2005;23(5):1011-1027.

4. Ferrara N, Gerber HP, LeCouter J. The biology of VEGF and its receptors. Nat Med. 2003;9(6):669-676.

5. Ferrara N, Hillan KJ, Gerber H-P, Novotny W. Discovery and development of bevacizumab, an anti-VEGF antibody for treating cancer. Nat Rev Drug Discov. 2004;3(5):391-400.

6. Hurwitz H, Fehrenbacher L, Novotny W, et al. Bevacizumab plus irinotecan, fluorouracil, and leucovorin for metastatic colorectal cancer. N Engl J Med. 2004;350(23):2335-2342.

7. Giantonio BJ, Catalano PJ, Meropol NJ, et al. Bevacizumab in combination with oxaliplatin, fluorouracil, and leucovorin (FOLFOX4) for previously treated metastatic colorectal cancer: results from the Eastern Cooperative Oncology Group Study E3200. J Clin Oncol. 2007;25(12):1539-1544.

8. Saltz LB, Clarke S, Díaz-Rubio E, et al. Bevacizumab in combination with oxaliplatin-based chemotherapy as first-line therapy in metastatic colorectal cancer: a randomized Phase III study. J Clin Oncol. 2008;26(12):2013-2019.

9. Saltz LB, Lenz H-J, Kindler HL, et al. Randomized Phase II trial of cetuximab, bevacizumab, and irinotecan compared with cetuximab and bevacizumab alone in irinotecan-refractory colorectal cancer: the BOND-2 Study. J Clin Oncol. 2007;25(29):4557-4561.

10. Miller K, Wang M, Gralow J, et al. Paclitaxel plus bevacizumab versus paclitaxel alone for metastatic breast cancer. $N$ Engl $J$ Med. 2007;357(26):2666-2676.

11. Vredenburgh JJ, Desjardins A, Herndon JE, et al. Bevacizumab plus irinotecan in recurrent glioblastoma multiforme. J Clin Oncol. 2007;25(30):4722-4729.

12. KreislTN, Kim L, Moore K, et al. Phase II trial of single-agent bevacizumab followed by bevacizumab plus irinotecan at tumor progression in recurrent glioblastoma. J Clin Oncol. 2009;27(5):740-745.

13. Escudier B, Pluzanska A, Koralewski P, et al. Bevacizumab plus interferon alfa-2a for treatment of metastatic renal cell carcinoma: a randomised, double-blind Phase III trial. Lancet. 2007;370(9605):2103-2111.

14. Margolin K, Gordon MS, Holmgren E, et al. Phase Ib trial of intravenous recombinant humanized monoclonal antibody to vascular endothelial growth factor in combination with chemotherapy in patients with advanced cancer: pharmacologic and long-term safety data. J Clin Oncol. 2001;19(3):851-856.

15. Sandler A, Gray R, Perry MC, et al. Paclitaxel-carboplatin alone or with bevacizumab for non-small-cell lung cancer. $N$ Engl $J$ Med. 2006;355(24):2542-2550.

16. Hanna N, Shepherd FA, Fossella FV, et al. Randomized Phase III trial of pemetrexed versus docetaxel in patients with non-small-cell lung cancer previously treated with chemotherapy. J Clin Oncol. 2004;22(9):1589-1597.

17. Peterson P, Park K, Fossella F, Gatzemeier U, John W, Scagliotti G. Is pemetrexed more effective in adenocarcinoma and large cell lung cancer than in squamous cell carcinoma? A retrospective analysis of a phase III trial of pemetrexed vs docetaxel in previously treated patients with advanced non-small cell lung cancer (NSCLC): P2-328. J Thorac Oncol. 2007;2(8):S851.

18. Socinski MA, Bondarenko IN, Karaseva NA, et al. Results of a randomized, phase III trial of nab-paclitaxel (nab-P) and carboplatin (C) compared with cremophor-based paclitaxel (P) and carboplatin as firstline therapy in advanced non-small cell lung cancer (NSCLC). ASCO Meeting Abstracts. 2010;28(Suppl 18):LBA7511.
19. Santos E, Martin-Zanca D, Reddy E, Pierotti M, Della Porta G, Barbacid M. Malignant activation of a K-ras oncogene in lung carcinoma but not in normal tissue of the same patient. Science. 1984;223(4637):661-664.

20. Suzuki Y, Orita M, Shiraishi M, Hayashi K, Sekiya T. Detection of ras gene mutations in human lung cancers by single-strand conformation polymorphism analysis of polymerase chain reaction products. Oncogene. 1990;5(7):1037-1043.

21. Schiller JH, Adak S, Feins RH, et al. Lack of prognostic significance of p53 and K-ras Mutations in primary resected non-small-cell lung cancer on E4592: a laboratory ancillary study on an Eastern Cooperative Oncology Group prospective randomized trial of postoperative adjuvant therapy. J Clin Oncol. 2001;19(2):448-457.

22. Mascaux C, Iannino N, Martin B, et al. The role of RAS oncogene in survival of patients with lung cancer: a systematic review of the literature with meta-analysis. Br J Cancer. 2005;92(1):131-139.

23. Tsao M-S, Aviel-Ronen S, Ding K, et al. Prognostic and predictive importance of p53 and RAS for adjuvant chemotherapy in non-smallcell lung cancer. J Clin Oncol. 2007;25(33):5240-5247.

24. Brugger W, Triller N, Blasinska-Morawiec M, et al. Prospective molecular marker analyses of EGFR and KRAS from a randomized placebo-controlled study of erlotinib maintenance therapy in advanced non-small-cell lung cancer. J Clin Oncol. 2011;29(31):4113-4120.

25. Jackman DM, Yeap BY, Lindeman NI, et al. Phase II Clinical Trial of chemotherapy-naïve patients $\geq 70$ years of age treated with erlotinib for advanced non-small-cell lung cancer. J Clin Oncol. 2007;25(7):760-766.

26. Miller VA, Riely GJ, Zakowski MF, et al. Molecular characteristics of bronchioloalveolar carcinoma and adenocarcinoma, bronchioloalveolar carcinoma subtype, predict response to erlotinib. J Clin Oncol. 2008;26(9):1472-1478.

27. Massarelli E, Varella-Garcia M, Tang X, et al. KRAS mutation is an important predictor of resistance to therapy with epidermal growth factor receptor tyrosine kinase inhibitors in non-small-cell lung cancer. Clin Cancer Res. 2007;13(10):2890-2896.

28. Pao W, Wang TY, Riely GJ, et al. KRAS mutations and primary resistance of lung adenocarcinomas to gefitinib or erlotinib. PLoS Med. 2005;2(1):57-61.

29. Brunner TB, Hahn SM, Gupta AK, Muschel RJ, McKenna WG, Bernhard EJ. Farnesyltransferase Inhibitors. Cancer Res. 2003; 63(18):5656-5668.

30. Appels NMGM, Beijnen JH, Schellens JHM. Development of farnesyl transferase inhibitors: a review. Oncologist. 2005;10(8):565-578.

31. Riely GJ, Johnson ML, Medina C, et al. A Phase II trial of salirasib in patients with lung adenocarcinomas with KRAS mutations. $J$ Thorac Oncol. 2011;6(8):1435-1437.

32. Oda K, Matsuoka Y, Funahashi A, Kitano H. A comprehensive pathway map of epidermal growth factor receptor signaling. Mol Syst Biol. 2005;1:2005.0010.

33. Shepherd FA, Rodrigues Pereira J, Ciuleanu T, et al. Erlotinib in previously treated non-small-cell lung cancer. $N$ Engl J Med. 2005; 353(2):123-132

34. Giaccone G, Gallegos Ruiz M, Le Chevalier T, et al. Erlotinib for frontline treatment of advanced non-small cell lung cancer: a Phase II study. Clin Cancer Res. 2006;12(20):6049-6055.

35. Cappuzzo F, Ciuleanu T, Stelmakh L, et al. Erlotinib as maintenance treatment in advanced non-small-cell lung cancer: a multicentre, randomised, placebo-controlled phase 3 study. Lancet Oncol. 2010; 11(6):521-529.

36. Lee D, Kim S-W, Suh C, Han Y, Lee J-S. Phase II study of erlotinib for chemotherapy-naïve patients with advanced or metastatic non-small cell lung cancer who are ineligible for platinum doublets. Cancer Chemother Pharmacol. 2011;67(1):35-39.

37. Hidalgo M, Siu LL, Nemunaitis J, et al. Phase I and pharmacologic study of OSI-774, an epidermal growth factor receptor tyrosine kinase inhibitor, in patients with advanced solid malignancies. J Clin Oncol. 2001;19(13):3267-3279. 
38. Baselga J, Rischin D, Ranson M, et al. Phase I safety, pharmacokinetic, and pharmacodynamic trial of ZD1839, a selective oral epidermal growth factor receptor tyrosine kinase inhibitor, in patients with five selected solid tumor types. J Clin Oncol. 2002;20(21):4292-4302.

39. Fukuoka M, Yano S, Giaccone G, et al. Multi-institutional randomized Phase II trial of gefitinib for previously treated patients with advanced non-small-cell lung cancer. J Clin Oncol. 2003;21(12):2237-2246.

40. Thatcher N, Chang A, Parikh P, et al. Gefitinib plus best supportive care in previously treated patients with refractory advanced non-small-cell lung cancer: results from a randomised, placebo-controlled, multicentre study (Iressa Survival Evaluation in Lung Cancer). Lancet. 2005;366(9496):1527-1537.

41. Niho S, Kubota K, Goto K, et al. First-line single agent treatment with gefitinib in patients with advanced non-small-cell lung cancer: a Phase II study. J Clin Oncol. 2006;24(1):64-69.

42. Zhang L, Shenglin M, Song X, et al. Efficacy, tolerability, and biomarker analyses from a phase III, randomized, placebo-controlled, parallel group study of gefitinib as maintenance therapy in patients with locally advanced or metastatic non-small cell lung cancer (NSCLC; INFORM; C-TONG 0804). J Clin Oncol. 2011;29(Suppl):Abstr LBA7511.

43. Lynch TJ, Bell DW, Sordella R, et al. Activating mutations in the epidermal growth factor receptor underlying responsiveness of non-small-cell lung cancer to gefitinib. $N$ Engl J Med. 2004;350(21):2129-2139.

44. Paez JG, Jänne PA, Lee JC, et al. EGFR Mutations in lung cancer: correlation with clinical response to gefitinib therapy. Science. 2004;304(5676):1497-1500.

45. Sharma SV, Bell DW, Settleman J, Haber DA. Epidermal growth factor receptor mutations in lung cancer. Nat Rev Cancer. 2007;7(3):169-181.

46. Herbst RS, Prager D, Hermann R, et al. TRIBUTE: a Phase III trial of erlotinib hydrochloride (OSI-774) combined with carboplatin and paclitaxel chemotherapy in advanced non-small-cell lung cancer. J Clin Oncol. 2005;23(25):5892-5899.

47. Gatzemeier U, Pluzanska A, Szczesna A, et al. Phase III study of erlotinib in combination with cisplatin and gemcitabine in advanced non-small-cell lung cancer: the Tarceva Lung Cancer Investigation Trial. J Clin Oncol. 2007;25(12):1545-1552.

48. Giaccone G, Herbst RS, Manegold C, et al. Gefitinib in combination with gemcitabine and cisplatin in advanced non-small-cell lung cancer: a Phase III trial - INTACT 1. J Clin Oncol. 2004;22(5):777-784.

49. Herbst RS, Giaccone G, Schiller JH, et al. Gefitinib in combination with paclitaxel and carboplatin in advanced non-small-cell lung cancer: a Phase III trial - INTACT 2. J Clin Oncol. 2004;22(5):785-794.

50. Mok TS, Wu Y-L, Thongprasert S, et al. Gefitinib or carboplatin-paclitaxel in pulmonary adenocarcinoma. $N$ Engl $J$ Med. 2009;361(10):947-957.

51. Maemondo M, Inoue A, Kobayashi K, et al. Gefitinib or chemotherapy for non-small-cell lung cancer with mutated EGFR. $N$ Engl $J$ Med. 2010;362(25):2380-2388.

52. Zhou C, Wu Y-L, Chen G, et al. Erlotinib versus chemotherapy as first-line treatment for patients with advanced EGFR mutationpositive non-small-cell lung cancer (OPTIMAL, CTONG-0802): a multicentre, open-label, randomised, phase 3 study. Lancet Oncol. 2011;12(8):735-742.

53. Rosell R, Gervais R, Vergnenegre A, et al. Erlotinib versus chemotherapy (CT) in advanced non-small cell lung cancer (NSCLC) patients (p) with epidermal growth factor receptor (EGFR) mutations: Interim results of the European Erlotinib Versus Chemotherapy (EURTAC) phase III randomized trial. J Clin Oncol. 2011;29(Suppl): Abstr 7503.

54. Mitsudomi T, Morita S, Yatabe Y, et al. Gefitinib versus cisplatin plus docetaxel in patients with non-small-cell lung cancer harbouring mutations of the epidermal growth factor receptor (WJTOG3405): an open label, randomised phase 3 trial. Lancet Oncol. 2010;11(2):121-128.

55. Dufort S, Richard M-J, Lantuejoul S, de Fraipont F. Pyrosequencing, a method approved to detect the two major EGFR mutations for anti EGFR therapy in NSCLC. J Exp Clin Cancer Res. 2011;30(1):57.
56. Nomoto K, Tsuta K, Takano T, et al. Detection of EGFR mutations in archived cytologic specimens of non-small cell lung cancer using high-resolution melting analysis. Am J Clin Pathol. 2006;126(4): 608-615.

57. Han H-S, Lim S-n, An JY, et al. Detection of EGFR mutation status in lung adenocarcinoma specimens with different proportions of tumor cells using two methods of differential sensitivity. J Thorac Oncol. 2012;7(2):355-364.

58. Asano H, Toyooka S, Tokumo M, et al. Detection of EGFR gene mutation in lung cancer by mutant-enriched polymerase chain reaction assay. Clin Cancer Res. 2006;12(1):43-48.

59. Naoki K, Soejima K, Okamoto H, et al. The PCR-invader method (structure-specific $5^{\prime}$ nuclease-based method), a sensitive method for detecting EGFR gene mutations in lung cancer specimens; comparison with direct sequencing. Int J Clin Oncol. 2011;16(4):335-344.

60. Sequist LV, Heist RS, Shaw AT, et al. Implementing multiplexed genotyping of non-small-cell lung cancers into routine clinical practice. Ann Oncol. 2011;22(12):2616-2624.

61. Pirker R, Herth FJF, Kerr KM, et al. Consensus for EGFR mutation testing in non-small cell lung cancer: results from a European workshop. J Thorac Oncol. 2010;5(10):1706-1713.

62. Greulich H, Chen TH, Feng W, et al. Oncogenic transformation by inhibitor-sensitive and -resistant EGFR mutants. PLoS Med. 2005;2(11):e313.

63. Kobayashi S, Boggon TJ, Dayaram T, et al. EGFR mutation and resistance of non-small-cell lung cancer to gefitinib. $N$ Engl J Med. 2005;352(8):786-792.

64. Bean J, Riely GJ, Balak M, et al. Acquired resistance to epidermal growth factor receptor kinase inhibitors associated with a novel T854A mutation in a patient with EGFR-mutant lung adenocarcinoma. Clin Cancer Res. 2008;14(22):7519-7525.

65. Yang C-H, Shih J-Y, Su W-C, et al. A phase II study of BIBW 2992 in patients with adenocarcinoma of the lung and activating EGFR/ HER1 mutations (LUX-LUNG 2). ESMO. May 19, 2010:Abstract 4132.

66. Shih J-Y, Yu C-J, Su W-C, et al. Activity of BIBW 2992, an irreversible EGFR/HER1 and HER2 TKI, in lung adenocarcinoma patients harboring less common EGFR mutations. ESMO. May 19, 2010: Abstract 4162.

67. Miller V, Hirsh V, Cadranel J, et al. Phase IIB/III double-blind randomized trial of afatinib (BIBW 2992, an irreversible inhibitor of the EGFR/HER1 and HER2) + best supportive care (BSC) versus placebo + BSC in patients with NSCLC failing 1-2 lines of chemotherapy and erlotinib or gefitinib (LUX-LUNG 1). ESMO. May 19, 2010: Abstract LBA1.

68. Yamamoto N, Katakami N, Atagi S, et al. A phase II trial of afatinib (BIBW 2992) in patients (pts) with advanced non-small cell lung cancer previously treated with erlotinib (E) or gefitinib (G). J Clin Oncol. 2011;29:(Suppl):Abstract 7524.

69. Janjigian YY, Groen HJ, Horn L, et al. Activity and tolerability of afatinib (BIBW 2992) and cetuximab in NSCLC patients with acquired resistance to erlotinib or gefitinib. J Clin Oncol. 2011;29:(Suppl): Abstract 7525.

70. Mok T, Spigel DR, Park K, et al. Efficacy and safety of PF299804 as first-line treatment of patients with advanced NSCLC selected for activating mutation of epidermal growth factor receptor (EGFR). ESMO. May 19, 2010:Abstract LBA18.

71. Ramalingam SS, Boyer MJ, Park K, et al. Randomized phase 2 study of PF299804, an irreversible human epidermal growth factor receptor (EGFR) inhibitor, versus erlotinib in patients with advanced non-small cell lung cancer after chemotherapy failure: quantitative and qualitative benefits. ESMO. May 19, 2010:Abstract 3778.

72. Boyer MJ, Blackhall FH, Park K, et al. Efficacy and safety of PF299804 versus erlotinib (E): a global, randomized phase II trial in patients (pts) with advanced non-small cell lung cancer (NSCLC) after failure of chemotherapy (CT). J Clin Oncol. 2010;28(Suppl 18):Abstract LBA7523. 
73. Park K, Heo DS, Cho B, et al. PF-00299804 (PF299) in Asian patients (pts) with non-small cell lung cancer (NSCLC) refractory to chemotherapy $(\mathrm{CT})$ and erlotinib $(\mathrm{E})$ or gefitinib $(\mathrm{G})$ : a phase $(\mathrm{P}) \mathrm{I} / \mathrm{II}$ study. $J$ Clin Oncol. 2010;28(Suppl 15):Abstract 7599.

74. Engelman JA, Zejnullahu K, Mitsudomi T, et al. MET amplification leads to gefitinib resistance in lung cancer by activating ERBB3 signaling. Science. 2007;316(5827):1039-1043.

75. Bean J, Brennan C, Shih J-Y, et al. MET amplification occurs with or without T790M mutations in EGFR mutant lung tumors with acquired resistance to gefitinib or erlotinib. Proc Natl Acad Sci U S A. 2007;104(52):20932-20937.

76. Spigel DR, Ervin TJ, Ramlau R, et al. Final efficacy results from OAM4558 g, a randomized phase II study evaluating MetMAb or placebo in combination with erlotinib in advanced NSCLC. J Clin Oncol. 2011;29(Suppl 15):Abstract 7505.

77. Sequist LV, von Pawel J, Garmey EG, et al. Randomized Phase II study of erlotinib plus tivantinib versus erlotinib plus placebo in previously treated non-small-cell lung cancer. J Clin Oncol. 2011;29(24):3307-3315.

78. Al-Saleem T, Al-Mondhiry H. Immunoproliferative small intestinal disease (IPSID): a model for mature B-cell neoplasms. Blood. 2005;105(6):2274-2280.

79. McNeely S, Conti C, Sheikh T, et al. Chk1 inhibition after replicative stress activates a double strand break response mediated by ATM and DNA-dependent protein kinase. Cell Cycle. 2010;9(5):995-1004.

80. Olaussen KA, Dunant A, Fouret P, et al. DNA repair by ERCC1 in non-small-cell lung cancer and cisplatin-based adjuvant chemotherapy. N Engl J Med. 2006;355(10):983-991.

81. Soda M, Choi YL, Enomoto M, et al. Identification of the transforming EML4-ALK fusion gene in non-small-cell lung cancer. Nature. 2007;448(7153):561-566.

82. Kwak EL, Camidge DR, Clark J, et al. Clinical activity observed in a phase I dose escalation trial of an oral c-met and ALK inhibitor, PF-02341066. J Clin Oncol. 2009;27(Suppl 15):Abstract 3509.

83. Kwak EL, Bang Y-J, Camidge DR, et al. Anaplastic lymphoma kinase inhibition in non-small-cell lung cancer. $N$ Engl J Med. 2010;363(18):1693-1703.
84. Camidge DR, Bang Y, Kwak EL, et al. Progression-free survival (PFS) from a phase I study of crizotinib (PF-02341066) in patients with ALKpositive non-small cell lung cancer (NSCLC). J Clin Oncol. 2011; 29(Suppl 15):Abstract 2501.

85. US Food and Drug Administration. FDA labeling information Crizotinib/Xalkori. 2011.

86. Yi ES, Boland JM, Maleszewski JJ, et al. Correlation of IHC and FISH for ALK gene rearrangement in non-small cell lung carcinoma: IHC score algorithm for FISH. J Thorac Oncol. 2011;6(3):459-465.

87. Paik JH, Choe G, Kim H, et al. Screening of anaplastic lymphoma kinase rearrangement by immunohistochemistry in non-small cell lung cancer: correlation with fluorescence in situ hybridization. $J$ Thorac Oncol. 2011;6(3):466-472.

88. US Food and Drug Administration. FDA approves Xalkori with companion diagnostic for a type of late-stage lung cancer. August 26, 2011 http://www.fda.gov/NewsEvents/Newsroom/PressAnnouncements/ ucm269856.htm. Accessed May 14, 2011.

89. Hirsch FR, Varella-Garcia M, Bunn PA, et al. Epidermal growth factor receptor in non-small-cell lung carcinomas: correlation between gene copy number and protein expression and impact on prognosis. J Clin Oncol. 2003;21(20):3798-3807.

90. Pirker R, Pereira JR, Szczesna A, et al. Cetuximab plus chemotherapy in patients with advanced non-small-cell lung cancer (FLEX): an open-label randomised phase III trial. Lancet. 2009;373(9674): 1525-1531.

91. Lynch TJ, Patel T, Dreisbach L, et al. Cetuximab and first-line taxane/ carboplatin chemotherapy in advanced non-small-cell lung cancer: results of the randomized multicenter Phase III trial BMS099. J Clin Oncol. 2010;28(6):911-917.

92. Pirker R, Pereira JR, von Pawel J, et al. EGFR expression as a predictor of survival for first-line chemotherapy plus cetuximab in patients with advanced non-small-cell lung cancer: analysis of data from the phase 3 FLEX study. Lancet Oncol. 2012;13(1):33-42.
Pharmacogenomics and Personalized Medicine

\section{Publish your work in this journal}

Pharmacogenomics and Personalized Medicine is an international, peerreviewed, open access journal characterizing the influence of genotype on pharmacology leading to the development of personalized treatment programs and individualized drug selection for improved safety, efficacy and sustainability. This journal is indexed on the American Chemical

\section{Dovepress}

Society's Chemical Abstracts Service (CAS). The manuscript management system is completely online and includes a very quick and fair peer-review system, which is all easy to use. Visit http://www.dovepress. com/testimonials.php to read real quotes from published authors. 